\title{
O SISTEMA DE QUOTAS E OS RECURSOS ARGUMENTATIVOS MANIFESTOS: UM ESTUDO DE CASO
}

\author{
Carla Callegaro Corrêa Kader \\ carlakader@via-rs.net \\ Débora Marshall \\ dmsm@mail.ufsm.br \\ Gabriela Quatrin Marzari \\ quatmarzari@yahoo.com \\ Liane Dal Molin Wissmann \\ Iwissmann@unijui.tche.br
}

\section{RESUMO}

Este trabalho retoma questões relativas ao Tratado da Argumentação, de PerelmanTyteca (1996), visto que se concentra na identificação de argumentos contrários e favoráveis ao sistema de quotas para afro-brasileiros, nas universidades brasileiras. Embora tenha como foco de análise os recursos argumentativos utilizados nos (três) textos selecionados, este estudo, a nosso ver, não tem a pretensão de examinar exaustivamente questões relativas à argumentatividade. Antes, visa à compreensão e decodificação das estratégias argumentativas - favoráveis ou contrárias — às quotas para negros nas universidades brasileiras.

\section{CONTEXTUALIZAÇÃO}

O debate gerado em torno do sistema de quotas adotado em algumas universidades brasileiras, garantindo que o destino de uma parcela de suas vagas seja reservado para a população negra, tem se acirrado nos diversos espaços de diálogos oferecidos pelos meios de comunicação como jornais, listas de discussão na Internet, sites pessoais, revistas, televisão e rádio.

O que se convencionou chamar de "discriminação positiva" é entendido pela Corte de Justiça da Comunidade Européia (CJCE'1) como uma medida que visa a eliminar ou reduzir as desigualdades que de fato podem existir na vida social. Também conhecida como "ação afirmativa", no Brasil, é interpretada como

\footnotetext{
uma estratégia de política social ou institucional voltada para alcançar a igualdade de oportunidades entre as pessoas, distinguindo e beneficiando grupos afetados por mecanismos discriminatórios com ações empreendidas em um tempo determinado, com o objetivo de alterar positivamente a situação
}

\footnotetext{
1 ZANETTI, Robson. A discriminação positiva em favor das mulheres. http://www.serrano.neves.nom.br/cgd/011201/13a025.htm
} 
de desvantagem desses grupos. (Glossário do Ministério do Trabalho e Emprego $)^{2}$

No entanto, a polêmica é antiga e abrange não somente os negros, mas mulheres reclamando a discriminação positiva em favor delas para que estas venham a ocupar o mesmo espaço que os homens no mercado de trabalho, ou, então, para deficientes físicos, assegurando, no caso do Brasil, $20 \%$ das vagas oferecidas em concursos públicos ${ }^{3}$.

Segundo Trindade $(2003)^{4}$, a nossa Lei Maior estabelece, como objetivo da Assembléia Nacional Constituinte, a instituição de "um Estado Democrático, destinado a assegurar o exercício dos direitos sociais (...), a igualdade e a justiça como valores supremos de uma sociedade fraterna, pluralista e sem preconceitos (...)", estabelecendo, como fundamentos da República Federativa do Brasil, a cidadania (inciso II) e a dignidade da pessoa humana (inciso III). Desta forma, como objetivos fundamentais, no artigo 3.- , encontramos o seguinte: I - construir uma sociedade livre, justa e solidária; III - erradicar a pobreza e a marginalização e reduzir as desigualdades sociais e regionais; IV - promover o bem de todos, sem preconceitos de origem, raça, sexo, cor, idade e quaisquer outras formas de discriminação.

Nesse sentido, a Universidade do Estado do Rio de Janeiro (UERJ) foi a primeira universidade do país a adotar o sistema de quotas e, mais recentemente, citamos o caso da Universidade de Brasília (UnB), que implementou o sistema de quotas em abril deste ano, visando a garantir $20 \%$ de suas vagas para estudantes negros. O ministro da Educação, Tarso Genro, também se manifestou nesse sentido. Genro chegou a esboçar sua intenção de editar, por Medida Provisória, uma política de quotas para as universidades, mas desistiu do intento ao tomar conhecimento de que atualmente existem 22 projetos sobre o tema no Congresso.

\footnotetext{
2 http://www.mte.gov.br/Temas/FiscaTrab/ProgramaCombate/Conteudo/Glossario.asp

3 Lei n.ำ 8.112/90, que estabeleceu o regime jurídico único para os servidores da União, contém, no $\S$ $2^{\circ}$ do seu art. $5^{\circ}$, o seguinte preceptivo: "Art. $5^{\circ}, \S 2^{\circ}$ - Às pessoas portadoras de deficiência é assegurado o direito de se inscrever em concurso público para provimento de cargo cujas atribuições sejam compatíveis com a deficiência de que são portadoras; para tais pessoas serão reservadas até $20 \%$ (vinte por cento) das vagas oferecidas no concurso."

${ }^{4}$ Trindade, Fernando. A Constitucionalidade da Discriminação Positiva. Disponível em: http://www2.senado.gov.br/conleg/artigos/direito/AConstitucionalidadedaDiscriminacao.pdf. Acesso em: 25 maio de 2004.
} 


\section{O PRESENTE TRABALHO}

A identificação e análise dos argumentos favoráveis às quotas para afro-brasileiros, nas universidades públicas do país, seguem os pressupostos teóricos de Reboul (2000), que retoma o Tratado da Argumentação (TA) de Perelman-Tyteca (1996). Com base no depoimento dos sujeitos definidos como S-1, S-2 e S-3, analisamos, no presente artigo, a distinção entre argumentos contrários e favoráveis ao programa de quotas no Brasil, chamando a atenção para os operadores do tipo lógico e argumentativo, moralizadores, índices de avaliação, dentre outros recursos lingüísticos reveladores da opinião dos falantes.

Longe de ser encerrado, o debate sobre as quotas permanece aceso e merece atenção no que tange aos argumentos que são utilizados de parte a parte. Nossa intenção é analisá-los mais a fundo, tentando identificar quais os argumentos utilizados, tanto contrários quanto favoráveis, e como eles se organizam para tornar esses discursos mais persuasivos. Para tanto, foram coletados exemplares de textos argumentativos, presentes na conhecida lista de discussão da "Comunidade Virtual de Linguagem $(C V L)^{5}$, no período de abril a junho de 2004, que versavam sobre o tema das quotas para negros nas universidades.

Tomando como base a análise do TA, de Perelman-Tyteca (1996), e as contribuições feitas por Reboul (2000), no livro Introdução à Retórica, os referidos argumentos serão analisados no sentido de identificar como estão organizados, que recursos argumentativos são utilizados e, conseqüentemente, em quais dos quatro tipos de argumentos eles se encaixam, a saber: argumentos quase lógicos (primeiro tipo), argumentos fundados na estrutura do real (segundo tipo), argumentos que fundamentam a estrutura do real (terceiro tipo) e argumentos por dissociação das noções (quarto tipo).

\section{A ANÁLISE}

Conforme indicado anteriormente, analisamos argumentações ditas contrárias e favoráveis ao sistema de quotas para negros nas universidades brasileiras, com base no TA, de Perelman-Tyteca (1996). Nesse sentido, apresentamos primeiramente os

\footnotetext{
${ }^{5}$ Site da CVL disponível em: http://groups.yahoo.com/group/CVL/.
} 
argumentos favoráveis à adoção de tal sistema, para, logo a seguir, abordarmos os argumentos contrários, tomando como corpus deste estudo três depoimentos de participantes/membros da CVL, identificados como S-1, S-2 e S-3, que enviaram suas mensagens nos dias 18 e 19 de maio de 2004. Salientamos que as mensagens utilizadas nos excertos foram mantidas tal qual grafadas e enviadas, embora apresentem algumas inconsistências por se tratar de uma escrita até certo ponto informal, sem grandes preocupações e/ou restrições quanto à forma, como acontece com a maioria das listas de discussão na Internet.

\subsection{AS RAZÕES PARA SER A FAVOR E OS RECURSOS UTILIZADOS}

De acordo com a análise realizada, a mensagem enviada por S-1 apresenta argumentos favoráveis à política de quotas, revelando o seu posicionamento já na explicitação do argumento apresentado no terceiro parágrafo do texto, conforme atesta o Excerto 1:

\section{Excerto 1}

Sou a favor das quotas e, por isso, também gostaria de desabafar, mesmo sabendo que o desabafo mais oportuno para a ocasião seja o desabafo daqueles cujo acesso à educação tem sido dificultado pela condição social, à qual encontram-se atrelados não apenas os diferentes modos de falar, como já sabemos, mas, principalmente, a origem étnica.

Portanto, a tese defendida pelo S-1 define-se como: "[...] o acesso à educação tem sido dificultado pela condição social, à qual encontram-se atrelados não apenas os diferentes modos de falar, como já sabemos, mas, principalmente, a origem étnica”. É preciso destacar que, ao longo do debate sobre o tema das quotas, promovido na CVL, os participantes procuram discutir eticamente todos os pontos de vista, mostrando-se a favor ou contra o sistema e sustentando suas opiniões por meio de argumentos pertinentes. Esse aspecto peculiar da discussão travada entre os "cevelistas" pode ser percebido, na mensagem de S-1, pelo uso de marcadores argumentativos, como os que destacamos no Excerto 2: 


\section{Excerto 2}

Longe de querer censurar aqueles que pensam diferente, mas, apenas querendo contribuir com mais uma opinião para o debate, gostaria de defender a política de quotas para negros na universidade PÚBLICA.

Quando se manifesta favoravelmente ao programa, S-1 apresenta uma série de argumentos sinalizados por marcadores argumentativos (Garcia, 1985), os quais dão sustentação à postura que assume ao longo da discussão sobre o programa de quotas. Nesse sentido, marcadores do tipo "mas", "entretanto", "portanto" estão presentes no texto e sua função, conforme destaca Garcia, é estabelecer uma relação lógica entre o conteúdo de duas proposições, sinalizando para o leitor o tipo de relação existente entre elas.

Do mesmo modo, S-1 faz uso de marcadores argumentativos, tais como, "pelo menos" e "apenas", para apresentar o seu ponto de vista em relação ao programa de quotas no Brasil. Semelhantemente, modalizadores são reiterados ao longo do texto: ora o autor defende a política de quotas utilizando-se do eixo do "crer", ora, do "saber", demonstrando, menor ou maior comprometimento em relação ao que fala. A título de exemplificação, apresentamos o Excerto 3, extraído do texto de S-1:

\section{Excerto 3}

Creio que, caso os nossos filhos não passem no vestibular das universidades públicas, o que é pouco provável, eles certamente teriam acesso garantido às universidades privadas.

Por meio de índices de avaliação, S-1 reitera o seu posicionamento no que se refere a essa política. Quando define como "ridícula" a teoria que considera algumas raças inferiores a outras, quando menciona a "facilidade de acesso aos diversos instrumentos facilitadores, como livros, computadores, Internet, etc.", e, finalmente, quando declara que "infelizmente" os negros não têm acesso à sala de discussões da CVL, o autor revela seus sentimentos, ou seja, a sua reprovação e discordância frente à situação que hoje se instaura entre os estudantes brasileiros. 
Em relação aos argumentos apresentados por S-1 para defender a tese, cabe ressaltarmos que tais argumentos partem de presunções ou premissas, sinalizadas por marcadores, os quais contribuem para que o(a) leitor(a) perceba a função dessas premissas no texto. Segundo Reboul (2000: 165), "as presunções têm função capital, pois constituem o que chamamos de 'verossímil', ou seja, o que todos admitem até prova em contrário". Uma dessas premissas pode ser encontrada no Excerto 4, marcada pela expressão "como sabemos":

\section{Excerto 4}

Como sabemos, o trabalho dos negros não serviu para melhorar a sua condição social, mas para beneficiar ou enriquecer o grupo que hoje conhecemos como "classe dominante".

A respeito dos argumentos propriamente ditos, apontamos os mais evidentes, dentre os quais, aqueles relacionados à ilustração, à analogia, à pergunta retórica e ao fato. Passamos, então, à identificação desses argumentos, a partir dos textos em anexo, e à explicação de seus efeitos à leitura e compreensão dos mesmos. Não pretendemos, no entanto, esgotar a discussão acerca de cada argumento detectado no texto, mas selecionar alguns, presentes pervasivamente ao longo da mensagem.

A princípio, três argumentos parecem se destacar: a analogia (Reboul, 2000: 185-189) e a ilustração (Idem: 181-183), considerados argumentos do terceiro tipo, ou seja, "que funda[m] a estrutura do real" (Reboul, 2000:181), e, finalmente, o fato, este não considerado essencialmente como argumento, mas como elemento do acordo prévio, de função argumentativa (Idem: 164). Além disso, as perguntas retóricas, lançadas pelo autor ao longo de todo o texto, contribuem fortemente para a argumentação.

Um exemplo de analogia apresentado na mensagem de S-1 é a comparação entre o caso das quotas e a situação dos antigos moradores do prédio Palace II, construído pelo empresário e ex-deputado Sérgio Naya, no Rio de Janeiro, que desabou em 1998. O Excerto 5 traz a passagem do texto em que o autor menciona essa comparação. 


\section{Excerto 5}

Em minha opinião, respeitar os direitos de reparação não significa considerar uma raça inferior ou incapaz. Como parâmetro para comparação, cito o caso dos antigos moradores do edifício Palace II, no Rio de Janeiro: têm direito a uma reparação pelos danos que sofreram devido à má fé com que agiram os construtores do edifício onde moravam. Será que respeitar esse direito significa considerar os moradores do Palace II inferiores ou incapazes?

As ilustrações propostas por S-1 dizem respeito à sua própria experiência de vida. Conforme afirma, para percebermos os prejuízos causados aos afro-descendentes no Brasil, não é preciso irmos muito longe. O Excerto 6 demonstra o argumento de S-1, conforme segue:

\section{Excerto 6}

Mas como a condição de escravo causou prejuízo aos afro-descendentes no Brasil? Não sei exatamente o que a maioria dos colegas pensam, mas eu verifico esse prejuízo sem precisar ir muito longe, bastando apenas olhar pela minha janela (...).

Para demonstrar esses prejuízos, S-1 compara a situação de seus filhos adolescentes, brancos e alunos de escola particular, com a de adolescentes, em sua maioria afro-descendentes, moradores da favela que ele enxerga ao olhar pela janela de sua casa. O Excerto 7 apresenta essa ilustração:

\section{Excerto 7}

Tenho dois filhos, brancos, alunos de escola particular, adolescentes que, por terem sido criados em um "ambiente letrado", adotaram a leitura como uma prática cotidiana. Por isso, se expressam facilmente através da escrita, muito próximo da "norma culta", e, muito em breve, através da língua inglesa, graças ao curso de idiomas que freqüentam, e graças também à facilidade de acesso aos diversos instrumentos facilitadores, como livros, computadores, internet, etc. Com isso, duvido muito que os adolescentes daquela favela, afro-descendentes, em sua maioria, consigam competir de igual para IGUAL com os nossos filhos em um exame de vestibular.

Ao longo do seu "desabafo", o autor apresenta vários fatos que, segundo ele, comprovam e demonstram como a condição de escravo causou prejuízo aos afrodescendentes no Brasil. De certa forma, o fato de que não há sequer uma pessoa afro-descendente entre os moradores do "condômino de classe média" onde S-1 habita também poderia ser considerado uma ilustração, posto que, conforme observa 
este autor, basta observar a favela próxima ao condomínio para constatar onde vivem os afro-descendentes na cidade. O Excerto 8 revela essa situação:

\section{Excerto 8}

Moro em Natal, em um típico "condomínio de classe média", no qual se pode constatar que não mora nenhuma pessoa de pele negra, a não ser os empregados dos moradores. Isso é um fato estranho, pois poderíamos pensar que não há afrodescendentes nesta cidade. Entretanto, olhando para fora do condomínio, percebe-se a existência de uma pequena comunidade bastante pobre, quase uma favela, com aproximadamente 50 casas, em cujas ruas se vê brincar as crianças, o que permite constatar onde estão os afro-descendentes desta cidade. ISSO É UM FATO.

Em relação às perguntas retóricas lançadas por S-1, em sua mensagem, constatamos que elas estão presentes, no decorrer do texto, incitando à reflexão e se prestando como estratégia muito forte na argumentação. A pergunta retórica pode ser considerada, segundo Reboul (2000: 167), uma figura relacionada ao acordo prévio entre os interlocutores. No Excerto 9, apresentamos a pergunta proposta por S-1, no quarto parágrafo do texto:

\section{Excerto 9}

Será que respeitar esse direito significa considerar os moradores do Palace II inferiores ou incapazes?

No oitavo parágrafo, podemos observar outro exemplo de pergunta retórica, sinalizada por vários pontos de interrogação, o que de fato contribui para a argumentação do texto. Ao utilizá-la, no Excerto 10, S-1 expressa sua opinião, democraticamente, sobre a implementação das quotas no sistema de ensino brasileiro. Através desse recurso, S-1 revela o seu posicionamento, embora de maneira aparentemente descomprometida.

\section{Excerto 10}

Isso me daria o direito de pensar que aquelas pessoas que moram na favela não trabalham, não se esforçam, ou são incapazes, ou preguiçosos? Por que será que a grande maioria dos moradores da favela são afro-descendentes? Seriam inferiores??????????? 


\subsection{AS RAZÕES PARA SER CONTRA E OS RECURSOS UTILIZADOS}

Conforme exposto anteriormente, embora S-1 coloque-se, já no início de sua argumentação, como estando a favor das quotas, seu texto é utilizado também como exemplo de argumentação contra, uma vez que ele historia e busca as mensagens anteriormente enviadas para dar sustentação à sua fala. $O$ primeiro movimento empregado por S-1 retoma a alegação feita por um colega de lista: "Todos são iguais e merecedores de respeito aos seus direitos de cidadão".

Sob esse ponto de vista, sua argumentação coloca-se no sentido de que, considerando a afirmação feita, todos teriam, também, a condição para atingir os mesmos objetivos, quaisquer que fossem eles. Conseqüentemente, não haveria necessidade das quotas para os negros chegarem até a universidade! Este argumento pertence, segundo a classificação utilizada, ao primeiro tipo, ou seja, é um argumento quase lógico, que faz apelo ao princípio de identidade e da justiça: tratar da mesma maneira os seres da mesma categoria. Ora, no caso de procedimento em forma contrária, cria-se então um precedente: a admissão de um ato autoriza a cometer atos semelhantes, conforme o Excerto 11, extraído do nono parágrafo.

\section{Excerto 11}

Assim como o direito dos moradores do Palace II, o direito dos afro-descendentes precisa ser respeitado, mesmo sabendo que todos são capazes, pois "Todos são iguais e merecedores de respeito aos seus direitos de cidadão".

No trecho a seguir, percebemos, por meio do argumento pragmático, a justificativa dada por outro colega da lista de discussões (CVL), trazida pelo autor, que, em pleno século 21, ainda há pessoas com a idéia de que existam raças inferiores, sendo esta afirmação um argumento contra as quotas, pois se não existe inferioridade entre as raças, qual seria a real razão e aplicabilidade das mesmas? Salientamos, com base em Reboul (2000: 173-174), que o argumento pragmático aprecia um ato ou um acontecimento em função de suas conseqüências favoráveis ou desfavoráveis: a quem refutar incumbirá uma justificativa, característico do trecho do Excerto 12, extraído do décimo parágrafo: 


\section{Excerto 12}

Em pleno século 21, ainda há pessoas acreditando que algumas raças são inferiores que outras. Além de ser ridícula, esse tipo de "teoria" fundamenta o preconceito, sórdido e inaceitável em qualquer circunstância".

Encontramos, na passagem abaixo, referência do autor à sua família e à sua condição social particular, criando uma situação imaginária para apresentar um argumento que pode ser interpretado tanto a favor das quotas quanto contrário a elas (Excerto 7). $\mathrm{O}$ emprego desse argumento, denominado argumento de direção, que prevê um fato de caráter predominantemente objetivo, pertence ao segundo tipo, ou seja, fundado na estrutura do real, portanto, cuja força reside justamente em se apoiar na experiência, nos fatos (re)conhecidos pelas pessoas e entre as coisas. Como o próprio Reboul (2000: 173) afirma: “(...) argumentar já não é mais implicar, é explicar (...)”. O Excerto 13, extraído do décimo sétimo parágrafo, atesta essa questão:

\section{Excerto 13}

Mas por que estou fazendo referência à minha família e à minha condição social particular? A resposta é uma constatação muito triste: mesmo sabendo quem é que realmente necessita das universidades públicas, eu confesso que prefiro ver os meus filhos lá dentro. Não serei hipócrita ao ponto de dizer que tiraria o meu filho da universidade pública para dar a vaga a um jovem carente. Estou sendo um pouco egoísta? Sim, certamente pela minha condição de pai, que deseja sempre o MELHOR para os filhos.

Nos parágrafos 19 e 20, encontramos o argumento de direção, através do qual o autor pode rejeitar algo, mesmo admitindo que em si é inofensivo ou bom, porque ele serviria de meio para um fim que não se deseja. O Excerto 14, retirado do décimonono e vigésimo parágrafos, comprova essa questão:

\section{Excerto 14}

"Ah! Mas essa é uma atitude populista".

Sim, e daí? Qual a culpa dos afro-descendentes se o governo é populista? Ora, combata-se o populismo, e não a criação de quotas.

A análise da mensagem de S-2 revela uma série de argumentos negativos sobre a questão das quotas. Para tanto, ele se utiliza de argumentos do terceiro tipo: que fundamentam a estrutura do real, tais como o exemplo, quando explica que só seria possível tornar o discurso realidade se as alterações não ficassem apenas nesse 
nível, mas no contexto em que se criou; e a comparação, quando chama atenção para o fato de que a "educação como um todo tá indo para o fundo do brejo".

\section{Excerto 15}

O discurso só pode criar alguma realidade se se conseguir alterar o espaço comunitário-enunciativo em que ele ocorre e de que decorre. Dado o discurso governamental das quotas, outros campos se pronunciam. E se, como você diz, a educação como um todo tá indo para o fundo do brejo, o discurso das quotas já começa mal.

No trecho a seguir, utilizando-se da exemplificação, S-2 indica outras mudanças ocorridas na sociedade que apenas pioraram a situação de grupos desfavorecidos. $O$ argumento centra-se no princípio de que o exemplo veiculado - deficientes integrados às classes normais - vai do fato à regra, isto é, a comparação das quotas na universidade não dará certo, como não deu certo a integração "forçada" de crianças especiais em turmas normais. Veja este argumento no Excerto abaixo:

\section{Excerto 16}

Veja que os deficientes foram "integrados" às classes normais e, com isso, viramse ainda mais discriminados, porque deles se passou a exigir comportamentos de não deficientes. $E$ os professores não aprenderam a lidar com eles. A integração aí piorou a situação. Nas classes especiais eles tinham uma melhor atenção.

Na conclusão da carta encontramos argumentos do terceiro tipo: exemplo anti-modelo e argumentos do quarto tipo: aparência/realidade. Nas considerações conclusivas, o autor, em tom fortemente emotivo, afirma o que não se deve imitar, fortalecendo a argumentação com base no anti-modelo. Para considerarmos a dissociação entre aparência-realidade, nesse exemplo cuja argumentação contrária às quotas é clara, basta entendermos que a realidade é a ausência de infra-estrututura, na maioria das cidades brasileiras onde a pobreza e a carência social são gritantes. Para S-2, não será o acesso dos negros à universidade que dará ao Brasil a aparência de país justo socialmente. 


\section{Excerto 17}

Do mesmo modo, o capitalismo internacional traduziu a anti-psiquiatria não evitar o confinamento e promover o tratamento ambulatorial, mas em acabar com os asilos e não dar assistência. A retórica dirá: agora os negros no Brasil têm acesso à universidade. E a realidade vai replicar: e a rede de esgotos, a comida, 0 emprego, etc. Melhoraram? Não tenho resposta para isso.

Na terceira mensagem analisada, S-3 introduz a sua opinião através de um argumento pragmático, explicando a afirmação de que as quotas seriam uma falácia e também uma forma de mascaração da ausência de uma política educacional séria. Ao fazer uso desse tipo de linha argumentativa, S-3 permite ao leitor "apreciar um ato ou um acontecimento em função de suas conseqüências favoráveis ou desfavoráveis" (Reboul, 2000: 174). Em decorrência de sua verossimilhança, sua força é tamanha que cabe a quem contestá-lo, justificar seu ato, no caso, provando que existe sim uma política educacional séria por parte do governo.

\section{Excerto 18}

Estou acompanhando o debate sobre as quotas e restrinjo-me a dizer que a maior falácia em torno do tema é a mascaração da ausência de uma política educacional séria, voltada para a educação pública de qualidade e investida de uma política de inserção social.

No segundo parágrafo, S-3 apresenta o argumento de autoridade, do segundo tipo, no qual uma professora que conhece muito bem e vive o sistema de ensino do país, principalmente por trabalhar em uma universidade, credita à iniciativa das quotas apenas mais uma forma de captação de investimentos, que, na sua opinião, não representa uma tentativa séria de melhorar as condições educacionais no Brasil.

\section{Excerto 19}

Entendo que as quotas são mais uma estratégia de incorporar os relatórios estatísticos para captação de investimentos, independentemente da oferta de um programa de educação para todos com qualidade real.

No quinto parágrafo, S-3 aponta o discurso populista das quotas como indicador de uma falsa preocupação com quem não está na escola. Para isso utiliza o argumento de direção, através do qual, descarta o sistema de quotas uma vez que, ao que parece, vê nele apenas mais uma forma desse tipo de discurso. 


\section{Excerto 20}

Aí, vem o discurso populista das quotas para fazer de conta que há preocupação real com quem não está na escola (de qualquer nível) e por isso não tem oportunidade de inserção social em condições dignas.

No sétimo parágrafo, encontramos os argumentos de identidade e regra de justiça, anteriormente citados por S-1, dados por meio da construção "Todo homem é igual independente de raça, sexo, credo, grupo social, etc".

\section{Excerto 21}

Todo homem é igual independentemente de raça, sexo, credo, grupo social, etc. A hora em que um governo resolver cumprir a Constituição, oferecendo educação pública de qualidade com número de vagas proporcional ao número de pleitantes e com recursos humanos e materiais suficientes para tender a demanda, não haverá mais que se falar em quotas.

No oitavo parágrafo, encontramos 0 argumento da analogia/comparação, que se concretiza através da comparação da situação vivida pelos negros à vivida pelos deficientes, pois, graças às quotas, os negros passariam a ser tratados não como iguais, mas como diferentes/deficientes, conforme atesta o Excerto abaixo:

\section{Excerto 22}

O povo, por sua vez, ao invés de se sentir prestigiado com essa indecente política de quotas deveria sentir-se ofendido por estar sendo tratado como carecedor de tratamento especial como é devido aos deficientes.

S-3 finaliza sua carta com o argumento de identidade e regra de justiça, citando diferentes elementos da sociedade e afirmando que todos somos iguais e merecedores de respeito aos nossos direitos de cidadão.

\section{Excerto 23}

Ser negro, pobre, índio, nordestino, ter esta ou aquela religião ou preferência sexual não devem ser tomados como referências de separatismo. Todos são iguais e merecedores de respeito aos seus direitos de cidadão. 


\section{CONSIDERAÇÕES FINAIS}

A identificação dos argumentos nem sempre é atividade simples. Como afirma Vogt (1980), se a linguagem falasse apenas à razão e constituísse, assim, uma ação sobre o entendimento dos homens, então ela seria apenas comunicação, mas sabemos que seu traço fundamental é a argumentatividade, a retórica, cujo ato lingüístico fundamental é $o$ ato de argumentar. Uma vez mapeadas as possibilidades dessas estratégias nessa aplicação, vale ressaltar a oportunidade do contato com um conteúdo extremamente relevante, contribuição para a compreensão de textos que divulgam os mecanismos das intenções discursivas.

\section{BIBLIOGRAFIA}

COMUNIDADE VIRTUAL DE LINGUAGEM (CVL). Disponível em: http://groups.yahoo.com/group/CVL. Acesso em: 18 abr. 2004.

GARCIA, O. Comunicação em prosa moderna. Rio de Janeiro: Editora da Fundação Getúlio Vargas, 1985.

PERELMAN, C. \& TYTECA, L. O. Tratado de Argumentação. São Paulo: Martins Fontes, 1996.

REBOUL, O. Introdução à retórica. São Paulo: Martins Fontes, 2000.

VOGT, C. A. Linguagem, pragmática e ideologia. Campinas: Hucitec, 1980. 